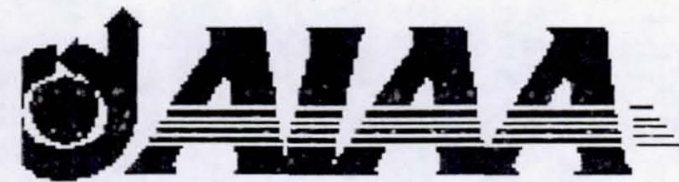

AIAA 2000-3856

Nuclear Pulse Propulsion - Orion and Beyond

G.R. Schmidt, J.A. Bonometti and P.J. Morton

NASA Marshall Space Flight Center

Huntsville, Alabama

36th AIAAJASME/SAE/ASEE Joint Propulsion Conference \& Exhibit

\author{
16-19 July 2000 \\ Huntsville, Alabama
}




\title{
NUCLEAR PULSE PROPULSION - ORION AND BEYOND
}

\author{
G.R. Schmidt, ${ }^{*}$ J.A. Bonometti** and P.J. Morton ${ }^{* *}$ \\ NASA Marshall Space Flight Center, Huntsville, Alabama 35812
}

\begin{abstract}
The race to the Moon dominated manned space flight during the 1960's, and culminated in Project Apollo, which placed 12 humans on the Moon. Unbeknownst to the public at that time, several U.S. government agencies sponsored a project that could have conceivably placed 150 people on the Moon, and eventually sent crewed expeditions to Mars and the outer planets. These feats could have possibly been accomplished during the same period of time as Apollo, and for approximately the same cost. The project, code-named Orion. featured an extraordinary propulsion method known as Nuclear Pulse Propulsion. The concept is probably as radical today as it was at the dawn of the space age. However, its development appeared to be so promising that it was onily by political and non-technical considerations that it was not used to extend humanity's reach throughout the solar system and quite possibly to the stars. This paper discusses the rationale for nuclear pulse propulsion and presents a general history of the concept, focusing particularly on Project Orion. It describes some of the reexaminations being done in this area and discusses some of the new ideas that could mitigate many of the political and environmental issues associated with the concept.
\end{abstract}

\section{Introduction}

The 20th century saw tremendous progress in the science and engineering of chemical rockets. These advances ushered in the deployment of extensive satellite systems in earth orbit, conveyance of sophisticated scientific probes into the farthest reaches of the solar system, and transport of humans to and from the Moon. Although these feats have been impressive, chemical rocketry has more or less reached the limits of its performance. Accomplishing the future goals of establishing human settlements on Mars, conducting rapid "omniplanetary" transportation throughout the solar system, and eventually travelling to the stars will require revolutionary advancements in propulsion capability
As always, cost is a principal factor driving the need for systems with much greater performance. However, when considering transportation of human crews over distances of billions of kilometers, safety becomes an equal if not more important concern. The biggest safety issues stem from the severe radiation environment of space and limitations imposed by human physiology and psychology. Although countermeasures, such as artificial gravity. could greatly mitigate these hazards. one of the most straightforward remedies is to significantly reduce trip time by travelling at very high-energy. hyperbolic trajectories. This will demand propulsion systems that can deliver far greater exhaust momentum per unit mass (i.e., specific impulse or Isp) than modern-day chemical rockets. and that can operate at significantly larger power densities than current high-performance electric propulsion systems.

Many advanced propulsion concepts have been identified that could. at least theoretically, meet these needs. The only problem is that virtually all of these technologies. such as fusion. antimatter and beamedenergy sails. have fundamental scientific issues and practical weaknesses that must be resolved before they can be seriously considered for actual applications.

For instance. fusion is limited by the fact that we are still far away from demonstrating a device having energy gains sufficient for commercial power, let alone space applications. Antimatter, while appealing due to its high specific energy, is severely hampered by extremely low propulsion efficiencies and the high costs of current antimatter production methods. Beamed energy offers great potential too, but requires materials far beyond current state-of-the-art and tremendous investment in power beaming infrastructure.

We are confident that many of these issues will be overcome, but there is no guarantee that systems based on these technologies could be fielded any time soon. This state-of-affairs points to the disappointing fact that none of the familiar advanced, high-power density propulsion concepts could, with a any degree of certainty, meet the goals of ambitious space flight within the next 30 or even 50 years. This is especially

\footnotetext{
* Deputy. Manager. Propulsion Research Center. Sr. Member AIAA.

* * Vuclear Propulsion Engineer. Propulsion Research Center. Member AIA 1 .

** $\quad$ Flight Sistems Engineer. Propulsion Research Center. Member AIA 1 .
}

Copyright O 2000 by the American Institute of Aeronautics and Astronautics. Inc. No copyright is asserted in the United States under Title 17. U.S. Code. The U.S. Government has a royalty-free license to exercise all rights under the copyright claimed here for Governmental purposes. All other rights are reserved by the copyright owner. 
true in light of the conservative fiscal environment of the post-Cold War era, which could limit the sizable investment needed to resolve the fundamental issues associated with these concepts. Moreover. developing actual vehicles based on these technologies and their required infrastructure could realistically cost on the order of hundreds of billions of dollars.

The rather bleak prospects for near-term highIsp high-power density propulsion improve however when we reconsider an extraordinary concept that grew out of nuclear weapons research during World War II. This concept, Nuclear Pulse Propulsion (NPP), represents a radical departure from conventional approaches to propulsion in that it utilizes the highly energetic and efficient energy release from nuclear explosions directly to produce thrust.

At first it would seem ridiculous to think that anything could survive the hundreds of thousanddegree temperatures at the periphery of a nuclear explosion, much less than the multi-million degree temperatures at the core. However as nuclear research advanced in the 1950's and 1960's, it became apparent that some materials could survive a nuclear detonation. and survive it well enough to provide a controllable conversion of blast energy into vehicle kinetic energy Most intriguing of all is that this approach could deliver specific impulses between 10.000 secs up to 100.000 secs with average power densities equal to or greater than chemical rockets, using existing technology.

The development of nuclear pulse propulsion during the 1950's and 1960's looked so promising that it was only through political and non-technical circumstances that it never became a reality. The bulk of this work occurred under the Orion program. a 7year project sponsored by the U.S. government from 1958 to 1965 . Had the program progressed to flight status, it is conceivable that the U.S. would have been able to place large bases on the Moon and send human crews to Mars, Jupiter and Saturn within the same time period as Apollo, and possibly for the same cost.

It is highly unlikely that the Orion envisioned back then would be acceptable by today's political and environmental standards. However, it does provide an excellent starting point for presenting some new ideas on nuclear pulse propulsion, which could deliver not only better performance than the original concept but could mitigate many of the issues associated with nuclear proliferation, environment contamination, and costly deployment in space.

\section{Origin of the Concept}

The idea of using a series of explosive pulses to propel a rocket vehicle can be traced back to Hermann Ganswindt. who published his ideas in the $1890^{\circ}$ s. [1] and R.B. Gostkowski. who issued the tirst scientific study of a concept using dynamite charges in 1900. [2]
These studies identified the two main issues in attaining a high Isp with this type of system. First is the energy per unit mass or specific vield of the detonations. The effective exhaust velocity and Isp are proportional to the square root of the energy distributed over the entire mass of the explosive charge, and point to the need to achieve as high of specific yield as possible. The second consideration is designing the vehicle to cope with the mechanical and thermal effects of the blast. which places a maximum limit on the utilizable energy.

The next significant step was the idea of using an explosive charge with much higher specific energy than dynamite. namely the atom bomb. In contrast with chemical explosives, the specific energies of nuclear reactions are so high that vehicle design constraints will limit the performance before the energy limit is reached. Uranium fission has an energy density of $-7.8 \times 10 \mathrm{MJ} / \mathrm{kg}$, corresponding to a maximum theoretical Isp of $\sim 1.3 \times 10^{6} \mathrm{sec}$. Surprisingly, this value is only half the maximum Isp attainable from fusion of Deuterium and Helium-3, which yields a product kinetic energy equivalent to $\sim 2.2 \times 10^{6}$ secs.

A proposal for use of fission-based explosives was first made by Stanislaus Ulam in 1946. followed by some preliminary calculations by F. Reines and Ulam in 1947. The first full mathematical treatment of the concept was published by Cornelius Everett and Ulam in 1955. [3] The U.S. Atomic Energy Commission was awarded a patent for the concept, termed "external nuclear pulse method," following initial application in 1959. [4]

The earliest physical demonstration and proof of the concept's merit occurred in an experiment conceived by physicist Lew Allen. Code-named "Viper." the experiment was conducted at the Eniwetok Island nuclear facility in the Pacific Ocean, and involved detonating a 20-kiloton nuclear device 10 meters away from two $\sim 1$-meter-diameter, graphitecoated steel spheres. [5] The wires holding the spheres were vaporized immediately, but not so for the spheres themselves. Some time later and several kilometers from ground zero, the spheres were recovered, with only a few thousandths of an inch of graphite ablated from their surfaces. [6] Most importantly, their interiors were completely unscathed.

\section{Types of Concepts}

Two basic types of nuclear pulse concepts have been examined over the years, and these are shown schematically in Fig. 1. [7] These concepts share many common features. and differ primarily in how momentum from the nuclear blast is converted to thrust. In all cases. an individual explosive device (i.e.. pulse unit) is ejected from the vehicle and detonated at a predetermined standoff distance from the rear. The resulting explosion vaporizes the entire pulse 
unit and causes this "propellant" to expand as a highenergy plasma, with some fraction interacting with the vehicle and providing thrust. A large number of pulses take place. probably at equal intervals.

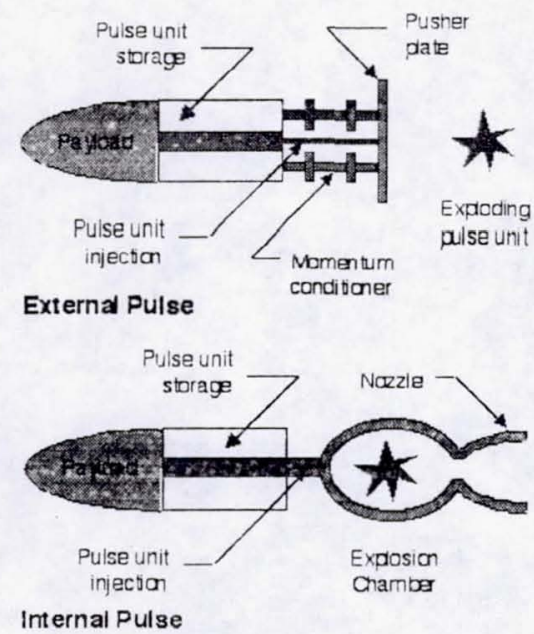

Figure 1: NPP Concepts

\section{External NPP}

This concept was historically the first to be conceived. The pulse takes place at some distance from a pusher plate, which intercepts and absorbs the shock of the explosion. The momentum conditioning unit smoothes out the momentum transfer between pulses to provide a nearly constant acceleration, and returns the plate to its proper location for the next pulse.

The advantage of this approach is that no attempt is made to confine the explosion. Thus, it circumvents the material temperature limits associated with confined concepts, such as solid and gas core nuclear thermal rockets. The interaction time of the propellant with the vehicle is so short that essentially no heat transfer occurs. The "temperatures" in the propellant cloud may be $\sim 10^{6} \mathrm{~K}$, but as the interaction time can be as low as $\sim 0.1 \mathrm{msec}$, only a small amount of material is ablated and lost. This pulsed nature is essential to the concept's feasibility, for if such high temperatures were applied for any extended length of time, the vehicle would be destroyed.

The Isp attainable with the external concept is proportional to the product of the propellant impingement velocity against the pusher plate and the fraction of pulse unit mass striking it. The impingement velocity is limited by pusher plate ablation, and is probably in the range of 100 to 200 $\mathrm{km}$ per second. The pulse unit fraction is determined by design of the explosive charge and the stand-off distance, and is in the range of 10 to $50 \%$. The resulting Isp limits are approximately 3.000 to 10,000 seconds.

\section{External NPP with Pusher Plate/Magnetic Field}

The limits on Isp due to ablation and spallation can be overcome by using a magnetic field to shield the surface from the high energy plasma. Magnetic field lines are generated parallel to the surface of a conducting pusher plate and as the plasma from the explosion expands it pushes the field lines against the conductor, increasing flux density. The increased magnetic pressure slows down the plasma, thus reversing its direction and accelerating it away from the pusher plate.

The impulse is transferred to the plate by magnetic interactions which spread out the force and protect the plate's surface from particle impingement. Therefore, the propellant particle energies can be higher than for an unshielded plate, and the Isp's attained with the system can also be greater.

Magnetic shielding was first mentioned by Everett and Ulam. [3] and the feature has become standard on the high-power fusion pulse vehicles studied following Orion. It is important to note that plasma confinement using magnetic fields is not perfect, and any high temperature neutral particles will be unaffected. In generai, however, magnetic shielding offers the only method of attaining Isp in excess of $10^{6}$ secs, while non-magnetic systems will probably be limited to $\sim 10^{4}$ secs.

\section{Internal NPP}

In this concept, the explosion takes place inside a pressure vessel from which heated propellant is expanded through a conventional nozzle. When this method was conceived, it was supposed that use of an enclosed "reaction chamber" and nozzle would eliminate the energy losses associated with isotropic external expansion and lead to greater performance.

Propellant (liquid hydrogen or water) is fed into the pressure vessel radially through the wall, and serves as a coolant. The explosion occurs at the center of the vessel, propagating a shock wave through the propellant until it is reflected from the walls. This wave is reflected back and forth in the vessel, increasing the internal energy of the hydrogen until equilibrium is established. This takes a few milliseconds, after which the vessel is refilled with propellant. The expansion process is continued until the previous initial conditions in the vessel are reestablished, and the cycle is repeated.

Studies in the 1960's concluded that Isp greater than 1,400 seconds would require very heavy engines. [8] There are two main limitations to the performance of an internal system. One is radiation heating most of the radiation emitted in the form of neutrons and $\gamma$-rays is deposited into the chamber wall. Thus, the vehicle requires cooling, and this is the dominant 
performance-limiting factor in the internal design. The resulting Isp limit depends on the energy derived from the explosion, but it is generally less than 1.500 secs - at least an order of magnitude worse than that of an external system with the same pulse unit mass.

The other limiting factor is the higher mass of the internal vehicles. Studies showed that the minimum mass of an external system will always be less than that for an internal system for the same payload and mission.

\section{Project Orion}

The most extensive effort on fission-based nuclear pulse propulsion was performed in Project Orion. The results obtained during its seven year lifetime from 1958 to 1965 were so promising that it deserves serious consideration today, especially in light of the serious technological obstacles posed by some of the other advanced propulsion technologies being considered for ambitious human space flight.

An excellent description of the project's history is given by Martin and Bond [7]. The following represents a condensed version of the historical summaries in that paper.

\section{The Beginning (1957 - 1958)}

Orion began in 1958 at the General Atomic Division of General Dynamics in San Diego, California. The originator and driving force behind the project was Theodore Taylor, a former weapon designer at Los Alamos who seeked a nuclear propulsion system that would regain American prestige in space in the wake of Sputnik.

Taylor had encountered the nuclear pulse propulsion concept at Los Alamos. Being an expert at making small bombs at a time when the drive was toward high-yield weapons, Taylor conceived a system in which the propellant mass was incorporated along with the nuclear charge in simple "pulse units", rather than the cumbersome separate disk/charge arrangement in Ulam's original proposal. Taylor adopted Ulam's pusher-plate idea, but instead of propellant disks, he combined propellant and bomb into a single pulse unit.

Taylor and Francis de Hoffman, the founder of General Atomic, persuaded Freeman Dyson, a theoretical physicist at Princeton's Institute for Advanced Study to come to San Diego to work on Orion during the 1958-1959 academic year. Taylor and Dyson were convinced that the approach to space flight being pursued by NASA was flawed. Chemical rockets, in their opinion, were very expensive, had very limited payloads, and were essentially useless for flights beyond the Moon. The Orion team aimed for a spaceship that was simple, rugged, roomy, and affordable. Taylor originally called for a ground launch, probably from the U.S. nuclear test site in Nevada. The vehicle. which is shown in Fig. 2 , looked like the tip of a bullet, was $\sim 80$-meters high and had a pusher plate $\sim 40$-meters in diameter. Analyses showed that the bigger the pusher plate, the better the performance

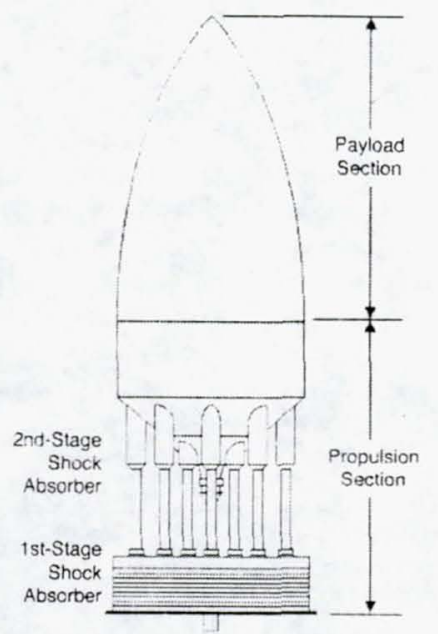

Figure 2: Early Orion Concept

The mass of the vehicle on takeoff would have been on the order of 10,000 tonnes - most of which would have gone into orbit. At takeoff, the 0.1 kiloton-yield pulse units would be ejected at a frequency of 1 per second. As the vehicle accelerated, the rate would slow down and the yield would increase until 20-kiloton pulses would have been detonated every ten seconds. The vehicle would fly straight up until it cleared the atmosphere so as to minimize radioactive contamination.

Taylor and Dyson began developing plans for human exploration through much of the solar system. The original Orion design called for 2,000 pulse units, far more than the number necessary to attain Earth escape velocity. Their bold vision was evident in the motto embraced at the time, "Mars by 1965 , Saturn by 1970." One hundred and fifty people could have lived aboard in relative comfort, and the useful payload would have been measured in thousands of tonnes. Orion would have been built with the robustness of a sea-going vessel, not requiring the excruciating weightsaving measures needed for chemically-propelled spacecraft.

The cost of fielding a flight-operational system was estimated to be $\$ 100$ million per year for a 12 -year development program. However, this figure does not include development costs for the thousands of smaller items that such a program would require (e.g.. spacesuits and scientific instruments). The Orion program would have most likely utilized the products from military weapons programs and existing civilian space projects. Still, even if this estimate was off by a 
factor of 20 , the revised total would have been only $\$ 24$ billion, roughly the same cost as the Apollo program.

The ARPA Years (1958 - 1960)

The Orion team realized early that the U.S. government had to become involved if the project was to have any chance of progressing beyond the research stage. In April 1958 Taylor gave a presentation to the Advanced Research Agency (ARPA) of the Department of Defense (DoD). The following July, after a good deal of negotiation, an award of \$1 million was made to cover 10 months of work. It was at this time that the code name of Orion was assigned.

Shortly after the start of the project, NASA was formed and took over all the civil space projects funded by ARPA, while the Air Force laid claim to all military projects. Orion remained the only major project under ARPA charge, as neither NASA nor the Air Force regarded it as a valuable asset. Taylor's efforts to interest NASA at this stage failed, which is difficult to understand in light of the growing interest in going to the Moon.

At the end of 1958 an award of $\$ 400.000$ was made to the project and the following August another million dollars was placed at Orion's disposal to cover the following year's work. The team grew to about 40 members, with the overall project responsibility falling to Frederic de Hoffman. Taylor was appointed project director with Jim Nance as assistant director (Nance later took over as director when Taylor left the project in 1963).

At this time, the Orion team built a series of flight models, called Putt-Putts, to test whether or not pusher plates made of aluminum could survive the momentary intense temperatures and pressures created by chemical explosives. Figure 2 shows a photograph of one of these models on display in the National Air and Space Museum in Washington, D.C.

A 100-meter flight in November 1959 (Fig. 3), propelled by six charges, successfully demonstrated that impulsive flight could be stable. These experiments also proved that the plate should be thick in the middle and tapered toward the edges to maximize its strength to weight ratio.

The durability of the plate was a major issue. The expanding plasma of each explosion could have a temperature of several tens of thousands of Kelvins even when the explosion occurred hundreds of feet from the plate. Following the lead of the Eniwetok tests, a scheme was devised to spray graphite-based grease onto the plate between blasts. Extensive work was done on plate erosion using an explosive-driven helium plasma generator. The experimenters found that the plate would be exposed to extreme temperatures for only about one millisecond during each explosion, and that the ablation would occur only within a thin surface

\begin{abstract}
layer of the plate the duration of high temperatures was so shor that wer. little heat flowed into the plate. and active coulthy wannecessary. The experimenters concluded that either duminum or steel would be durable enough to act us plate material.
\end{abstract}
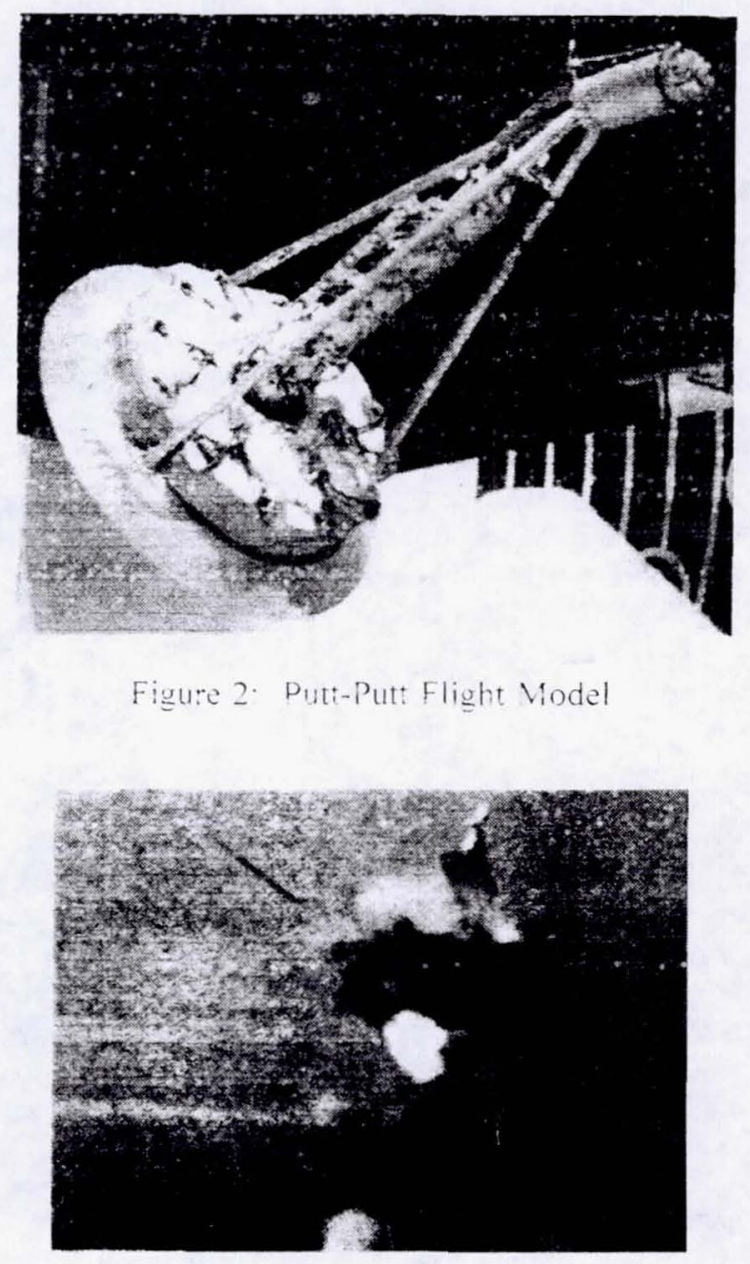

Figure 3: Putt-Putt Flight Test

The Air Force Years (1960 - 1963)

A juncture came in late 1959. when ARPA decided it could no longer support Orion on nationalsecurity grounds. Taylor had no choice but to approach the Air Force for funds. Although it was a hard sell, the Air Force finally decided to pick up Orion, but only on the condition that a military use be found for it. The Air Force contacts were sympathetic to the goals of space exploration. but felt that their hands were tied.

The plan was to use Orion as a weapon platform in polar orthit that could pass over ever? point on the Earth's surface It could also protect itself easily against attach by small numbers of missiles. However. this idea had the same disadvantages as the 
early bomb-carrying satellite proposals. Terminal guidance would have been a problem. since the technology for accurately steering warheads had not yet been developed. Furthermore, both the U.S. and the Soviet Union were deploying missiles that were capable of reaching their targets in fifteen minutes with multi-megaton warheads, making orbiting bomb platforms irrelevant.

Little firm information is available but it does seem certain that the vehicles were intended to drive a 900 tonne payload to low earth orbit or to escape from a threatening surface launch and return to its operating position. The vehicle was most likely propelled by small yield explosions of about 0.01 kilotons, released from the vehicle at 10 second intervals and detonated between 30 and 300 meters behind the pusher plate. The gross launch weight of the basic vehicle was quoted as 3,630 tonnes, and the acceleration ranged from 20 to $90 \mathrm{~m} / \mathrm{s}^{2}$. The Isp of 4,000 to $6,000 \mathrm{sec}$, along with an average vehicle acceleration of $\geq 1.25 \mathrm{~g}$ would enable direct launch from the Earth's surface or sub-orbital startup. Such vehicles would have a propulsion module inert mass fraction of 0.3 to 0.4 and pulsing intervals of about $1 \mathrm{sec}$.

\section{The NASA Years $(1963-1965)$}

Robert McNamara, Defense Secretary under the Kennedy Administration, felt that Orion was not a military asset. His department consistently rejected any increase in funding for the project, which effectively limited it to a feasibility study. Taylor and Dyson knew that another money source had to be found if a flyable vehicle was to be built, and NASA was the only remaining option. Accordingly, Taylor and Nance made at least two trips to Marshall Space Flight Center (MSFC) in Huntsville, Alabama.

At this time, Werner Von Braun and his MSFC team were developing the Saturn moon rocket. Consequently, the Orion team produced a new, "first generation" concept that abandoned ground launch and boosted into orbit as a Saturn V upper stage. A schematic of the vehicle is shown in Fig. 4.

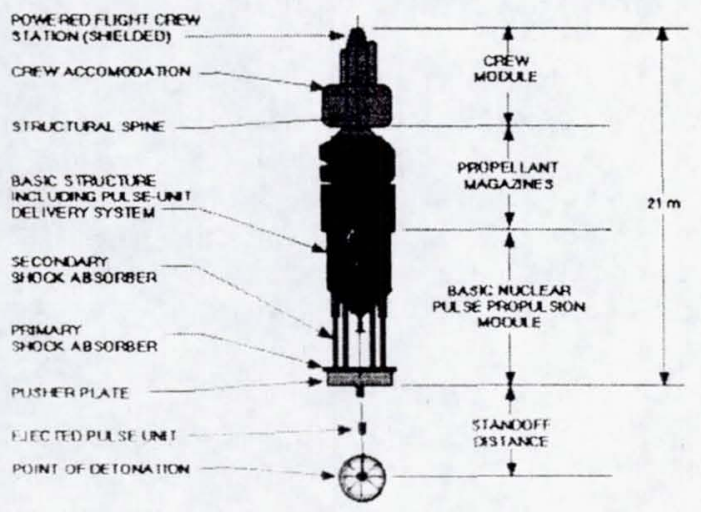

Figure 4: Orion Spacecraft — NASA Version
The core of the vehicle was a $-100,000 \mathrm{~kg}$ propulsion module with a 10 -meter diameter pusher plate. which was set by the Saturn diameter envelope. This rather small diameter restricted Isp to 1800 to 2500 secs. While extremely low by nuclear pulse standards, this tigure far exceeded those of other nuclear rocket designs. The shock absorber system had two sections: a primary unit made up of toroidal pneumatic bags located directly behind the pusher plate, and a secondary unit of four telescoping shocks connecting the pusher plate assembly to the rest of the spacecraft.

Two or possibly three Saturn V's would have been required to put this vehicle into orbit, and some on-orbit assembly would be required. Several mission profiles were considered - the one developed in greatest detail was for a Mars mission. Eight astronauts, with around 100 tonnes of equipment and supplies, could have made a round trip to Mars in 125 days (most current plans call for one-way times of at least nine months). Another impressive figure is that as much as $45 \%$ of the gross vehicle weight in Earth orbit could have been payload. Presumably the flight would have been made when Mars was nearest to the Earth; still, so much energy was available that almost the fastest-possible path between the planets could have been chosen.

An assessment at that time placed the development costs at $\$ 1.5$ billion, which suggests a superior economics for nuclear pulse spaceships. Dyson also felt that Orion's advantages were greatly diluted by using a chemical booster - the Saturn V's would have represented over $50 \%$ of the total cost.

Von Braun became an enthusiastic Orion supporter, but he was unable to make headway for increased support among higher-level NASA officials. In addition to the general injunction against nuclear power, very practical objections were raised, such as what would happen if a Saturn carrying a propulsion module with hundreds of bombs aboard should explode, and was it possible to guarantee that not a single bomb would explode or even rupture? Although NASA feared a public-relations disaster and was reluctant to provide money, its Office of Manned Space Flight was sufficiently interested to fund another study.

\section{Orion's Death}

A fateful blow was dealt to Orion in August 1963 with signing of the nuclear test-ban treaty. Although the tests required for development of an Orion vehicle were now illegal under international law, it was still possible that an exemption could be granted for programs that were demonstrably peaceful. However, there is no doubt that the treaty greatly diminished Orion's political support. Another problem was that 
because Orion was a classified project, very few people in the engineering and scientific communities were aware of its existence. In an attempt to rectify this, Orion's manager. Jim Nance, lobbied the Air Force to declassify at least a broad outline of the work that had been done. Eventually it agreed, and Nance published a brief description of the "first generation" vehicle in October 1964

The Air Force, meanwhile, had become impatient with NASA's noncommittal approach. It was willing to be a partner only if NASA would contribute significant funds. Hard-pressed by the demands of Apollo, NASA made its decision in December 1964 and announced publicly that it would not continue to fund Orion. The Air Force then announced discontinuation of all funding, thus terminating Orion. All told, approximately $\$ 11$ million had been spent on Orion over nearly seven years. Freeman Dyson stressed the importance of the Orion story "...because this is the first time in modern history that a major expansion of human technology has been suppressed for political reasons." In retrospect, there were other issues besides politics, and these included: (1) the inherent large size of the vehicle made full scale tests difficult and costly, (2) the nuclear test ban treaty excluded testing in the atmosphere or in space, (3) the NERVA solid core nuclear engine provided strong competition, and (4) no specific mission existed which demanded such a high performance system.

\section{Orion's Legacy}

Although Orion employed fission as the mode of energy release, use of fusion was always viewed as the next logical step in the evolution to ever-higher performance. One advantage of fusion is the higher specific energy of the reaction, but for charged particle products, this is only several times that of fission. The main advantage of fusion is that there is no minimum mass criticality limit, and the detonation can be made very small - yields on the order of 0.001 kiloton and lower.

In 1968, Freeman Dyson was the first to propose application of fusion pulse units for the much more ambitious goal of interstellar flight. His rationale was simple - the debris velocity of fusion explosions was in the range of 3,000 to $30,000 \mathrm{~km} / \mathrm{sec}$, and the geometry of a hemispherical pusher plate would reduce the effective interception velocity four-fold to 750 $15,000 \mathrm{~km} / \mathrm{s}$ (Isp between 75,000 and $1.5 \times 10^{6} \mathrm{secs}$ ). This made mission velocities of $10^{3}$ to $10^{4} \mathrm{~km} / \mathrm{sec}$ possible.

Dyson considered two kinds of concepts. The more conservative design was energy-limited, having a large enough pusher plate to safely absorb all the thermal energy of the impinging explosion, without melting. The other momentum-limited concept defined the upper region of performance. Each of these vehicles was immense and capable of transporting a colony of thousands of people to a nearby star. It would take -1.000 years for the energy-limited design to reach Alpha Centauri, while the momentum-limited case would take a mere century.

A new era in thinking about nuclear pulse propulsion began in the late 1960's and early 1970's. Spurred by optimism for controlled fusion for power generation, researchers ignored use of fissionable material, and began to focus on igniting small "millikiloton" fusion microexplosions. By lowering the energy of each fusion explosion, the structural mass of a spacecraft could be reduced. Microexplosions also promised significantly reduced fuel costs because there would be no need for fissionable material or elaborate pulse unit structures.

Soon microexplosion designs began to push toward theoretical Isp levels near $10^{6}$ secs. implying exhaust velocities near $3 \%$ of light velocity. The pusher plate become a powerful magnetic field. which would channel charged particles into an exhaust, and pulse repetition rates increased to hundreds per second. Converging laser beams. electron beams or other driver energy sources would ignite the fusion pellets by inertially compressing and confining the fuel. Some of the energy of the microexplosions would be tapped electromagnetically to provide power for the lasers and the pusher plate magnetic fields, that is a bootstrap process. These systems clearly have extraordinary design requirements and push technological limits. A vehicle propelled by a million-second Isp engine could in theory visit any location within the solar system in a matter of months.

Members of the British Interplanetary Society took up the challenge of fusion microexplosion propulsion and conducted the most elaborate study to date of a robotic interstellar vehicle. From 1973 to 1978, the team of 13 members worked on Project Daedalus, a two-stage fusion microexplosion spacecraft designed to send a scientific payload of 450 tons at $12 \%$ light speed on a one-way, 50 -year fly-through mission to Barnard's star, 5.9 light years distant.

The $10^{6} \mathrm{sec}$ Isp engines used deuterium and helium-3 fusion fuel; the latter component, because of its terrestrial scarcity, would have to be "mined" from Jupiter's atmosphere before the flight. Daedulus would accelerate for about four years under the incessant din of 50,000 tons of pellets ignited 250 times per second by relativistic electron beams. Total departure mass, fully-fueled, 54,000 tons - almost all propellant.

More recent investigations of fusion microexplosions have considered use of laser inertial confinement, with Lawrence Livermore's VISTA concept. [9] and use of combined microfission fusion with an antimatter trigger. [10] Although the driver technology in all these cases is very different. the basic concepts all have their roots in the earlier concepts of fusion-based nuclear pulse propulsion. 


\section{Reconsidering Nuclear Pulse Propulsion}

Interest in nuclear pulse propulsion never really died with Orion, it merely evolved into concepts based on what many view as the tamer and more politically acceptable process of nuclear fusion. In retrospect, this shift in interest was probably premature and based on overly optimistic projections of fusion's viability. We now know that the challenge of fusion is much more difficult than originally envisioned. In fact, fusion for spacecraft applications may in some respects be harder to achieve than for commercial power, due to the need for lightweight subsystems and high gain. [11]

Recognizing the formidable challenges of fusion, perhaps it would be wise to take a step back and reconsider the use of fission-driven pulses. There have been many changes to the technological and political landscape over the last 30 to 40 years, and it is possible that fission-based systems could be made safe. affordable, and even better performing than the designs considered in the Orion program.

The most sensitive issue with Orion was its use of self-actuating nuclear devices. Ironically, this was also one of its main strengths, since it eliminated the need for massive driver and energy storage hardware onboard the spacecraft. Still, aimost anyone who has been exposed to the concept feels uncomfortable about this aspect, and rightly so, since it raises a myriad of issues regarding testing, nuclear proliferation, and national security. This is particularly true with the yield of the devices originally considered in the Orion program. Although small by weapon standards, they were nonetheless in the 0.1 to 10 kiloton range, and drove the need for large, robust spacecraft designs.

There has likely been considerable progress in the actuation of explosive fissionable charges over the last 30 to 40 years, and this technology could be applied to realize smaller yield detonations than those baselined for Orion. The main challenge is not achieving lowyield devices per se, but being able to do so with high energy per unit mass (i.e., high specific yield). Of course, such information would undoubtedly be classified and unavailable for openly reviewed spacecraft evaluations. However, the possibility is there and could bring the yields down into more acceptable ranges.

Another major difference between now and the time of Orion is the dramatic improvement in materials technology. Orion's pusher plate and momentum transfer assemblies were based on 1950's and 1960's technology, and featured common materials, such as steel and aluminum. Research over the last 40 years has opened the prospects of advanced carbon structures and lightweight refractory materials which could greatly reduce the mass and improve the ablative characteristics of nuclear pulse systems. The latter consideration is especially important since it tends to place an upper limit on the performance in terms of Isp. Smaller, high-specific yield pulses combined with more ablation resistant materials would reduce minimum standoff distance requirements, thereby increasing Isp considerably.

Even with the reduction in yield and improvements in performance, use of self-actuating nuclear charges would still be a political issue. However, it can be argued that in some ways the environment may be more accommodating today than it was during the politically-charged days of the Cold War. In many ways, international cooperation is more prevalent today, and could conceivably be extended to the peaceful application of nuclear pulse technology. It does provide a productive avenue for disposing of the substantial stockpiles of weapons-grade fissionable material that exist throughout the world, and the environmental contamination would be negligible if used at a sufficient distance outside low earth orbit.

There is no doubt that political acceptance of such an idea would demand convincing technological need and international involvement. As of now, there are several propulsion concepts that could be used for human missions to Mars. However with conservative projections of technological readiness, these missions would be constrained to 2 to 3 year durations.

If the need arose to conduct a Mars mission much faster (say in a year or less) or if there were a need to transport human or large payloads as rapidly as possible to destinations in the outer solar system (e.g., Jupiter and beyond), then the use of nuclear pulse becomes quite compelling. If such missions involved extensive international cooperation, then there may be more acceptance for this type of technology.

Perhaps the most promising avenue for use of fission-based nuclear pulse lies in the direction of microfission processes. In these schemes, subcritical targets of fissile material are compressed via a mechanism onboard the spacecraft in a manner similar to that in fusion-based concepts. The big difference is that the energy requirements to drive a fission sample to supercriticality and high burn-up fractions is substantially less than that for comparable fusion processes.

The advantages of this type of approach are clear. It eliminates the concerns over having vehicles that carry fully contained "bombs." Because these systems rely on a compression and energizing source from the spacecraft, they cannot be used as a weapon, at least in any conventional way. Not only does this take care of the concern over storing thousands of small bombs in close vicinity, but it also removes many of the issues concerning nuclear proliferation.

Only a few studies of this approach have been conducted, but the results look very promising. It may prove to be a more realistic intermediate step between the propulsion systems of today and the fusionpropelled concepts of tomorrow. 


\section{References}

1. Ganswindt, H., Das jungste Gericht, Berlin, 1899.

2. Gostkowski, R.B., Die Ziet, p. 53, Vienna, 28 July 1900 .

3. Everett, C.J. and Ulam, S.M., "On a method of propulsion of projectiles by means of external nuclear explosions," LAMS-1955 (1955).

(Declassified, Aug 25, 1976).

4. "Nuclear propelled vehicle, such as a rocket," British Patent Specification, No. 877, 392, 13 Sept, 1961.

5. Flora, M.R., "Project Orion: Its Life, Death, and Possible Rebirth," Submitted for the Robert H. Goddard Historical Essay Contest, Nov 24, 1992.

6. Mallove, E. and Matloff, G., The Starflight Handbook: a pioneer's guide to interstellar travel," John Wiley \& Sons, Inc., ISBN $04716191241989,1989$.

7. Martin, A.R. and Bond, A., "Nuclear Pulse Propulsion: A Historical Review of an Advanced Propulsion Concept," J. of the British Interplanetary Society, Vol. 32, pp 283-310, 1979.

8. Platt, E.A. and Hanner, D.W., "The effective specific impulse of a pulsed rocket engine," UCRL-12296 (1965). Presented at AIAA Propulsion Joint Specialist Conference, 14-18 June 1965

9. Orth, C. D., Klein, G., Sercel, J., Hoffman, N., Murray, K., and Chang-Diaz, F., "VISTA: A Vehicle for Interplanetary Space transport Applications Powered By Inertial Confinement Fusion," Report UCRL-LR-1 10500, University of California, Lawrence Livermore National Laboratory, Livermore, CA 94550 (1998).

10. Gaidos, G., Lewis, R. A., Smith, G. A., Dundore, B. and Chakrabarti, S., "AntiprotonCatalyzed Microfission/Fusion Propulsion Systems for Exploration of the Outer Solar System and Beyond," Space Technology and Applications International Forum, El-Genk, M. S. ed., 1998.

11. Chakrabarti, S. and Schmidt, G.R., "Impact of Energy Gain and Subsystem Characteristics on Fusion Propulsion Performance," AIAA 20003613, July, 2000. 